\title{
Piezoelectric Energy Generation from Vehicle Traffic with Technoeconomic Analysis
}

\author{
Hiba Najini and Senthil Arumugam Muthukumaraswamy \\ Department of Electrical, Electronic and Computer Engineering, School of Engineering \& Physical Sciences, Heriot-Watt University, \\ 1294345 Dubai, UAE \\ Correspondence should be addressed to Hiba Najini; hn57@hw.ac.uk
}

Received 17 April 2016; Revised 21 August 2016; Accepted 28 September 2016; Published 13 February 2017

Academic Editor: Michael McAleer

Copyright (C) 2017 Hiba Najini and Senthil Arumugam Muthukumaraswamy. This is an open access article distributed under the Creative Commons Attribution License, which permits unrestricted use, distribution, and reproduction in any medium, provided the original work is properly cited.

\begin{abstract}
This paper presents a technical simulation based system to support the concept of generating energy from road traffic using piezoelectric materials. The simulation based system design replicates a real life system implementation. It investigates practicality and feasibility using a real-time simulation platform known as MATLAB-Simulink. The system design structure was proposed considering factors involved with the field of material sciences for piezoelectric generator modeling and field of power electronics for additional components in producing a realist outcome. It also ensures ease of vehicle performance, as this system utilizes energy source derived as kinetic energy released from vehicles into electrical power output, that is, obtained by harnessing kinetic energy due to strain of vehicles over asphalt road surface. Due to the real-time simulation platform, the system simulation predicts the effective global carbon footprint. In addition to evaluating technical viability, a technoeconomical business analysis provides a strategic perspective. By using the simulation based power generation results, an estimation of implementation cost and payback time in real life (for United Arab Emirates) was derived, hence validating and predicting real-time economic outcome. This is followed by a comparative study with other sources of renewable energy based on levelized energy cost factor that justifies the performance of the proposed system over other renewable energy sources, in support of providing an economical solution on reducing global carbon footprint.
\end{abstract}

\section{Introduction}

The universal law of conservation energy states that energy can neither be created nor be destroyed but converted from one form of energy into another form of energy [1]. This process of conversion is commonly addressed as energy transfer that enables energy to reside at different state or transform into another type of energy via generators or transducer. Thus, this paper explores the notion of harnessing kinetic energy released from vehicle traffic in form of vibration due to speed of travel and strain caused due to gravity to power street lights, traffic signal, radars, and residential houses, in turn reducing greenhouse emission by minimizing energy requirement from the grid. However, the penetration of kinetic energy from surface of the asphalt road depends on the structure and quality of piezoelectric transducers embedded beneath. Moreover, it is believed to be more efficient than wind or solar energy in terms of economic aspects based on levelized energy cost (LEC).
This paper presents relevant study from our previous published work [2] that provides an insight into the principles of finite element analysis, power electronics, and the classic plate theory involved in the system designing. The first stage of designing used classic plate theory as a base structure or its foundation to build up the system formulation in correspondance to its application. This also includes the exploration of basic principle of mechanisms involved in the proposed method on structuring of piezoelectric transducers using finite element analysis (FEA) and power electronic devices to attain increased levels of kinetic energy absorption. The Simulink model projected anticipated design with real life safety systems, keeping in mind the end goal which legitimized the hypotheses to a realistic and sensible scale. In addition to modeling, this article predicts and estimates power generation using real-time MATLAB-Simulink platform. After this, the estimated energy production was used to check for economic viability in terms of business aspects to estimate cost of investment, return-on-investment (ROI), and 
internal-rate-of-return along with carbon emission analysis for the proposed system. Lastly, brief levelized energy cost computations were carried out to justify the relevance of the proposed system to existing technology. After this, the outcomes acquired were completely inspected to infer to the accompanying conclusions.

\section{Previous Work}

Piezoelectric energy generation utilizes the strain caused by vehicles over asphalt road surface due to gravity and harnessing kinetic energy or vibrations from moving vehicles. These vibrations from moving vehicles are nothing but imbalance caused by strain of a tire on gravel road (asphalt road). In order to capture and harness such an energy, a piezoelectric transducer by nature is a perfect device as piezoelectric materials react to "compression" to produce electrical output. Since asphalt road comprises finer gravel and a structure almost similar to cement roads, piezoelectric generator has to be highly sensitive and closer to impact in theory. In order to achieve a highly sensitive piezoelectric transducer, the selection and structure of material are vital, such that the material withstands various load conditions along with environmental factors. This leads to investigations amongst the existing material that exhibits maximum displacement such as barium titanate $\left(\mathrm{BiTiO}_{3}\right)$ and lead zirconate titanate (PZT) as performed in our previous study [2]. From our study, doping of PZT optimized piezoelectric and dielectric parameters in addition to its robust structure. However, PZT-5H was the most appropriate material under various experimental conditions in comparison to PZT-5H, PZT-4, and PZT-5A. For instance, it exhibits highest piezoelectric property from $25^{\circ}$ to $170^{\circ}$ which is within the Curie temperature and is appropriate for extreme external temperature (suitable for UAE). Moreover, in our study, the optimum design structures of transducers amongst pile type, multilayered, thunder, moonie, bridge, and cymbal type were also performed along with FEA to classify chemical properties of the elements in all possible structures. Modeling and the structuring of the piezoelectric transducer on its own involve the process of finite element analysis to select the appropriate material, namely, the lead zirconate titanate (PZT-5H), which is demonstrated in Figure 1. The figure formulates the optimum structure for the piezoelectric generator design.

From previous work [2], it was clear that the piezoelectric transducer design requires about 8 to $16 \mathrm{PZT}$ piles for $0.04 \mathrm{~m}^{2}$ road area where the PZT piles were of round shape and multilayering the structure of PZT was suggested to decrease the electric potential on pavement generator. In addition to finite structuring of the generator, implementation of this system requires slight alteration of road's foundation structure such that it behaves like a plate resting on Winkler foundation [3] that provides a spring-like structure to maximize the output power generated by amplifying the impact signal. However, this Winkler foundation aims to only enhance the strain and fluctuation of the vibration/kinetic energy harnessed by the transducer beneath the surface on miniscale range and not deteriorate the entire structure of asphalt road, thus providing a seamless energy harvester system. Moreover, Zhang et al.

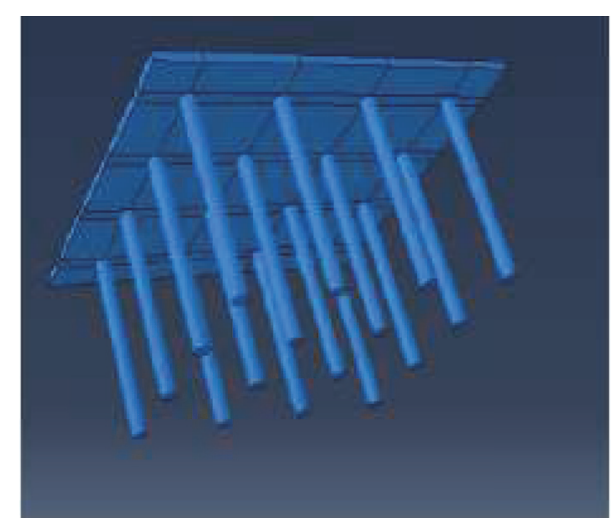

Figure 1: FEA of optimum piezoelectric transducer.

[3] had performed various analyses by considering shear and stress of the structure at various load conditions including effective load area to estimate the placement of a simple transducer. An effective output yielded an average power of $250 \mathrm{kWhr} / \mathrm{km}$ per lane with traffic rate of 20 vehicles $/ \mathrm{min}$, when transducers were placed at $5 \mathrm{cms}$ beneath the surface of the road captured vibrations and utilized deformation of road dynamics as its input source. In order to deduce deformation of road dynamic's response to estimate an overall power generation, an equation based mathematical modeling of pavement denoted by (2) produces the deformation response that deals with the classic plate theory based on KirchhoffLove plate theory and navies solution in conjunction with Fourier analysis, Cauchy's residue theorem and so on. In order to deduce the deformation of the pavement, the governing differential equation of the pavement is denoted by (1) that was obtained according to the Kirchhoff-Love plate theory [4] or commonly known as the classic plate theory [5]. This plate theory was blatantly hiding behind physics books which is relevant to this form of application.

$$
\begin{aligned}
& D \nabla^{4} \omega(x, y, t)+\rho h \frac{\partial \omega(x, y, t)}{\partial t^{2}}+K \omega(x, y, t) \\
& \quad=F(x, y, t), \\
& D\left[\frac{\partial^{4} \omega_{m}(x, t)}{\partial x^{4}}-2\left(\frac{m \pi}{b}\right)^{2} \frac{\partial^{2} \omega_{m}(x, t)}{\partial x^{2}}\right. \\
& \left.\quad+\left(\frac{m \pi}{b}\right)^{4} \omega_{m}(x, t)\right]+\rho h \frac{\partial^{2} \omega_{m}(x, t)}{\partial t^{2}}+K \omega_{m}(x, t) \\
& \quad=f_{m}(x, t),
\end{aligned}
$$

where $K$ is modulus of the subgrade, $\rho$ is density, and $t$ is time. However, the flexural rigidity of the pavement $D$ is determined by [3]

$$
D=\frac{E h^{3}}{12(1-\mu)},
$$

where $E$ is Young's modulus, $\mu$ is Poisson's ratio, and $h$ is thickness of the pavement. These equations represent road 


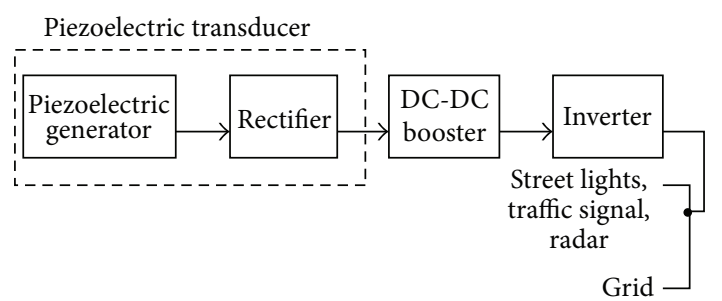

Figure 2: Process flow diagram.

structure as plates or Winkler foundation due to its elastic nature/bouncy foundation. However, this aspect only affects impact signal within the frequency range determined by the piezoelectric material and does not modify the road structure to a wobbly state. It only boosts the piezoelectric transducers. Then, the fourth-order displacement gradient is addressed by (4) with the Winkler foundation represented by the second and the third term of (4) [3]. Consider

$$
\begin{aligned}
& \nabla^{4} \omega(x, y, t) \\
& \quad=\left[\frac{\partial^{4} \omega(x, y, t)}{\partial x^{4}}+2 \frac{\partial^{4} \omega(x, y, t)}{\partial x^{2} \partial y^{2}}+\frac{\partial^{4} \omega(x, y, t)}{\partial y^{4}}\right] .
\end{aligned}
$$

Using (2), displacement of pavement due to load intensity of vehicle considering coefficient of friction was computed by applying boundary conditions and assuming the length of the pavement was considered to be infinite in the direction of motion and simply supported at edges. With the new found displacement and characteristic properties of the piezoelectric material, the output voltage and power of a single piezoelectric generator were determined, by incorporating all the parameters in the direct piezoelectric law, stated by (5) [57]. Consider

$$
C_{0} \frac{d V(t)}{d t}+\frac{V(t)}{R}=\frac{d Q(t)}{d t}
$$

These analogies and discussed methods [3, 4, 8, 9] were used to design the piezoelectric generator on MATLAB-Simulink and the system also comprises various other power electronic systems such as rectifiers, inverters, DC boost converter, LC filter, PWM modulation, and PI controller [10].

\section{Methodology}

This methodology is ideal for developed countries as the installation process requires revenue and the power generation is high voltage which requires proper transmission installation. First, a basic block design for this type was structured depicted by Figure 2.

The flow chart shown in Figure 2 represents the working process of the entire proposed system. From literature review, the system comprises a piezoelectric transducer that is to be embedded within the surface of the road at $5 \mathrm{cms}$ below the surface as per our previous studies [2]. These piezoelectric transducers capture the strain due to the mass of the vehicles, the kinetic energy due to moving traffic, and the vibrations caused due to the contact between the tire and the asphalt road surface as its input source of energy. The "piezoelectric generator" block then converts this input mechanical input (strain) energy source into electrical power output (AC power generation). Then this power is rectified into DC power source via the "rectifier" block. These blocks together form the piezoelectric transducer stage as observed from Figure 2. However, as mentioned earlier in literature review, design structure of piezoelectric generator and formulation of road foundation are the main process of generating electricity. Then the rectified output from the piezoelectric generator as seen from Figure 2 is doubled via "DC boost converter" system for the purpose of transmission. Next, the power produced is passed through the "inverter" block as indicated in Figure 2 that produces AC power output before supplying it to grid for further transmission.

3.1. Design Implementation of Simulink Model. This mechanism of system was carefully implemented using MATLABSimulink environment as observed in Figure 3; first a MATLAB scrip was written (provided in the Appendix) to replicate power generation of piezoelectric transducer as described in literature review and function of script is to take in

(i) dimensions of road;

(ii) load intensity due to

(a) average speed of vehicle,

(b) rate of traffic,

(c) friction of coefficient;

(iii) time duration (elapsed time of power generation).

The MATLAB script is essentially alternative modeling of the piezoelectric generator, utilizing the concepts and theories provided in Section 2 and (1), (2), and (5). However, the power generation of the system, known as load factor, depends on factors listed above as dimension of road determines number of piezoelectric transducers that would be embedded beneath surface of asphalt road. After that, the speed at which vehicle travels will have an impact on percentage of area in contact with surface of road that causes displacement within its surface. But displacement is directly related to displacement of piezoelectric transducer embedded. Therefore, MATLAB script was written (provided in Appendix) that incorporated piezoelectric material (PZT-5H) properties listed in Table 1. As the main aim of the MATLAB script is to vary the specifications for each city/country, this journal provides computed data and results that satisfy the speed regulations limited to cities in UAE including the vehicle weight, speed, and road temperature. (Specifically Dubai as speed limits are constrained to 80,100 , and $120 \mathrm{kmph}$.) Following this, the script was called within the Simulink model as "DATA" source. Following this, Simulink model (Figure 3) was implemented based on output readings derived from MATLAB script.

It can be seen that system is briefly subcategorized into four sections which are similar to those of block diagram observed in Figure 3, vis-a-vis the following: 


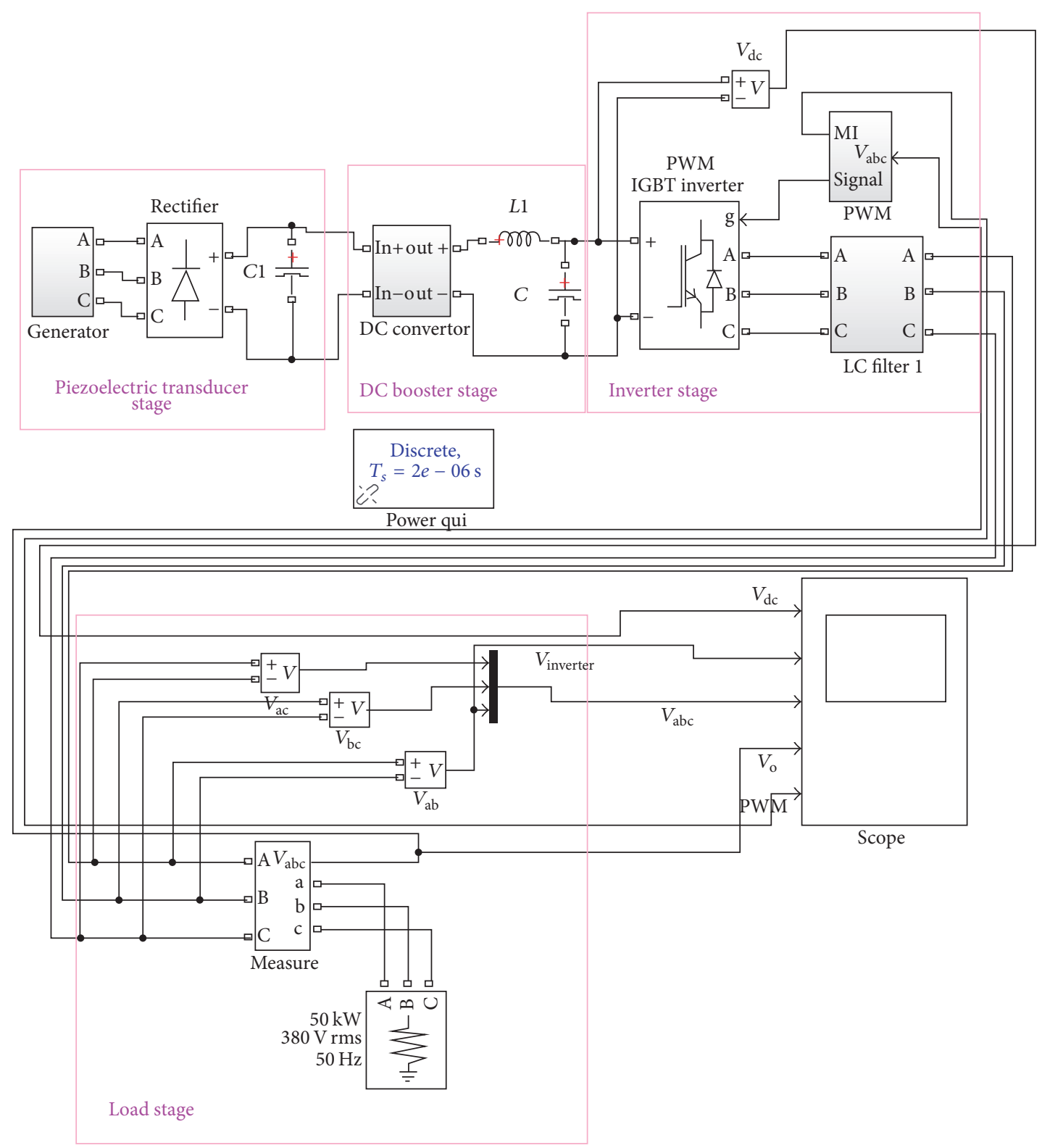

FIgURE 3: Design implementation of Simulink model.

(i) Piezoelectric transducer stage.

(ii) DC booster stage.

(iii) Inverter stage.

(iv) Output/load stage.

These stages after piezoelectric power generator stage are to rectify the generator power by extracting and canceling the ripple current and noise. The inverter stage is responsible for acting as a power oscillator, as they oscillate direct current supply into alternating current supply. However, in order to exert this effect, the transistors are controlled by a pulse width modulated signal to switch on and off a particular set of transistors to recreate the positive and the negative cycle. The frequency is usually chosen to be between 2 and $20 \mathrm{kHz}$ to minimize switching losses up to an extent. The switching is implemented as a multistage (to achieve high gain) MOSFET amplifier. MOSFETs are a type of transistor with a low onresistance and a high current-handling capacity. The PWM generator is controlled using PI (Proportional-Integral) controller with appropriate $K_{p}, K_{i}$ values to help maintain the average power produced after various stages, such that the input to the controller block is the output voltage generated by the entire system before transmission or supplying to a load. The value of $K_{p}$ and $K_{i}$ was found by the means of trial and error such that the modulation index of the PWM signal is to be maintained at unity. It works to transform the input signal at the required frequency by altering its switching frequency and sustaining the control over the voltage level. After this, the three-phase power is connected to "LC filter" block that acts as a passive filter which helps in maintaining the system 
reliability that improvises the output by minimizing the total harmonic distortion caused by lower frequency signal and signal interference caused during switching and modulation of the IGBTs or the MOSFET from the earlier stage. This block also helps in maintaining the signal-to-noise ratio and reducing the white noise created within the system during the transmission of energy across the various stages of the proposed system.

Moreover, the losses experienced in this system are mainly due to external power electronic devices within the proposed system that constitute losses from rectifier, $P W M$ modulation, PI controller, invertor, LC filter, and DC-DC boost converter systems. These losses experienced are mainly due to electrical components involved in circuit analogy of each power electronic system and switching losses that occur when pulse width is modulated. In addition to these losses, the following aspects were also considered that affect system performance:

(i) Load factor of piezoelectric generator as it may not capture all kinetic and vibration energy as it has unidirectional orientation.

(ii) Rectifier losses. (iii) DC booster losses due to switching of the MOSFETS.

(iv) Inverter losses.

(v) Switching losses due to PWM modulation for

(a) inverter,

(b) controller of DC boost converter.

\section{Power Analysis}

In order to estimate total power generated the main cause of power loss analysis is vital which is due to the supplementary components of the system such as the DC boost converter, rectifier, and the inverter. However, the energy produced has certain limitations as it does not capture all the kinetic energy from the vehicles and transform them into useful electrical energy. This is due to the variation in the frequency and speed of travel of the vehicle that is commonly defined as the input characteristic parameters. Therefore, the following formula gives an estimation of utilized kinetic energy from the vehicles at various speed of travel, that is, the impact of the load on the surface of the speed hump which is commonly known as the load intensity given by

$$
\text { Load Intensity }=\frac{\text { Mass of vehicle } * \text { coefficient of rolling friction } * \text { Contact tires }}{\text { area of contact } * \text { Speed of travel }} .
$$

These input characteristic parameters from Table 1 were incorporated in the MATLAB script that incorporates (1), (2), and (5) to estimate the power generation from one piezoelectric transducer device. By running the script it was found and concluded that one piezoelectric transducer device was able to produce $0.137 \mathrm{~W}$ from a four-wheeled vehicle with a traveling speed of $100 \mathrm{kmph}$, that is, $30 \mathrm{~m} / \mathrm{s}$. Similarly, the power generation was 0.085 and $0.204 \mathrm{~W}$ when the speed of travel was $80 \mathrm{kmph}$ and $120 \mathrm{kmph}$, respectively. The traveling speed represents the common speed limit structure in Dubai, UAE. These speed restrictions were considered in the MATLAB script as separate case studies. However, the script kept the transducer dimension constant in all case studies that is represented in Table 2.

Next, the number of piezoelectric devices required to be embedded within a one-kilometer stretch was estimated to be 3280 devices as per the dimensions of the transducers specified in Table 1. This number is less than the formulated value so as to minimize the cost of implementation to an extent and to compensate the misplacement of the device. Then, using the results of power generation from the transducer stage, Table 3 was computed to estimate the power generation of a one-kilometer stretch single lane road embedded with these piezoelectric transducer devices with the following assumptions:

(i) Traffic rate of 500 vehicles per hour.

(ii) Speed of travel $100 \mathrm{kmph}$.
From Table 3, it can be clearly seen that even though the traffic rate is 500 vehicles, the power generation is only affected by 444 vehicles as the speed of travel limits the amount of power generated. For instance, when a car travels over this piezoelectric embedded road at a speed of $100 \mathrm{kmph}$, it would take about 0.216 seconds to travel completely along its length about 6 meters of distance between the front edge and the rear edge of the vehicle. This time was calculated using a simple distance and speed relationship formula.

Similarly the load traffic rate applicable was 388.9 and 500 vehicles when the speed of travel was $80 \mathrm{kmph}$ and $120 \mathrm{kmph}$, respectively. Then, when the traffic rate is 100 vehicles per hour traveling at speed of $100 \mathrm{kmph}$, Table 4 was computed to represent the power generation.

From Table 4, it can be clearly observed that the traffic rate and the load traffic impact are the same as the speed of travel of $100 \mathrm{kmph}$ which is capable of generating power from 444 vehicles. However, for this condition of 100 vehicles per hour, the road can only see those many vehicles and the power generation in this scenario is limited due to the amount of traffic rate rather than the speed of travel in comparison to the previous case. However, these limitations due to the speed of travel and the traffic rate are what limits the power generations and are notably denoted as the type of capturing losses that determines the load factor of this type of power generation system.

Similarly the above analysis was used to estimate the power generation when the speed of travel was $120 \mathrm{kmph}$ and $80 \mathrm{kmph}$, respectively, in the next few sections. On 
TABLE 1: Piezoelectric material properties.

\begin{tabular}{lc}
\hline Parameter & Value \\
\hline Poisson's ratio $(\mu)$ & 0.15 \\
Young's modulus $E(\mathrm{Mpa})$ & 27560 \\
Density $(\rho)$ & 2323 \\
Winkler modulus $(K)(\mathrm{Mpa} / \mathrm{m})$ & 136 \\
Distributed load of vehicle $\left(p_{0}\right)(\mathrm{Mpa})$ & 0.267 \\
Distance between the moving loads $\left(2 d_{0}\right)$ & 1.22 \\
Length of the transducer $\left(l_{p}\right)$ & 0.1 \\
Width $\left(b_{p}\right)$ & 0.1 \\
Thickness $\left(h_{p}\right)$ & 0.01 \\
Elastic compliance constant, $s_{11}\left(\mathrm{pm}^{2} / \mathrm{N}\right)$ & 16.5 \\
Elastic compliance constant, $s_{12}\left(\mathrm{pm}^{2} / \mathrm{N}\right)$ & -5.74 \\
Piezoelectric constant, $d_{31}(\mathrm{pV} / \mathrm{m})$ & -274 \\
Permittivity, $\epsilon_{33}(\mathrm{nF} / \mathrm{m})$ & 30.06 \\
Resistive load $(\mathrm{k} \Omega)$ & 800 \\
\hline
\end{tabular}

TABLE 2: Transducer dimensions.

\begin{tabular}{lc}
\hline Parameter & Dimension $(\mathrm{cm})$ \\
\hline Length & 14 \\
Width & 14 \\
Depth & 2 \\
\hline
\end{tabular}

TABle 3: Power estimation from one-kilometer stretch road.

\begin{tabular}{lc}
\hline Number of piezoelectric transducers & 3280 \\
Traffic rate per hour & 500 \\
Speed of travel $(\mathrm{kmph})$ & 100 \\
Load traffic rate & 444.44 \\
Traffic rate per minute & 8.333 \\
Power/piezo/vehicles/km & 0.137 \\
Total power/piezo/km/hr & 57.083 \\
Total power $(\mathrm{Wmin})$ & 3120.556 \\
Total power $(\mathrm{kWhr})$ & 187.233 \\
\hline
\end{tabular}

TABLE 4: Total power generation per piezoelectric transducer.

\begin{tabular}{lc}
\hline Number of piezoelectric transducers & 3280 \\
Traffic rate per hour & 100 \\
Speed of travel (kmph) & 100 \\
Load traffic rate & 100 \\
Traffic rate per minute & 1.667 \\
Power/piezo/vehicles/km & 0.137 \\
Total power/piezo/km/hr & 13.7 \\
Total power $(\mathrm{Wmin})$ & 748.936 \\
Total power $(\mathrm{kWhr})$ & 44.936 \\
\hline
\end{tabular}

the other hand, the power generation when the traffic rate was 100 vehicles per hour was found to be of the same value as indicated from Table 4 for both speeds of travel. After the power generation from the piezoelectric transducer stage as per Figure 3, it was seen that the ac power from the piezoelectric transducer flows into the next component
TABle 5: Rectifier losses.

\begin{tabular}{lc}
\hline & Rectifier losses \\
\hline Snubber resistance & 100 \\
Snubber capacitance & 0.0000001 \\
Diode resistance & 0.001 \\
Total diode resistance & 0.006 \\
Diode $V$ _drop & 0.8 \\
Number of diodes & 6 \\
Total voltage drop & 4.8 \\
Total rectifier loss (W) & 0.0049 \\
\hline
\end{tabular}

TABLE 6: Power losses in a DC boost converter.

\begin{tabular}{lc}
\hline \multicolumn{2}{c}{ DC boost converter losses } \\
\hline MOSFET-switching loss (W) & 1.18 \\
M-resistance & 0.1 \\
M-internal diode impedance & 0.01 \\
M-internal diode $V$ forward & 0.2 \\
M-total diode losses & 0.00021 \\
M-snubber resistance & 100000 \\
M-snubber capacitance & $\mathrm{INF}$ \\
M-snubber losses & 0.1 \\
D-resistance & 0.001 \\
D-forward voltage drop & 0.8 \\
Diode losses & 0.0008 \\
S-snubber resistance & 500 \\
Resistor & 0.5 \\
Snubber losses + external resistance loss & 0.0005005 \\
Inductor & 0.0002 \\
Capacitor & 0.00005 \\
Total converter loss (W) & 1.1815106 \\
\hline
\end{tabular}

known as the rectifier where the AC output power was rectified into a $D C$ output with a value of 0.137 Watts from the MATLAB script. However this rectifier block suffered few power losses as per the simulation model and all the parameters involved in the power loss from this block are evaluated in Table 5 .

From Table 5, it can be evidently observed that the losses from the rectifier component block are mainly due to the diodes that are used to rectify the AC into DC output. Then the losses are due to the snubber circuitry within the rectifier block. This snubber circuitry is shock absorber circuit used to prevent an electrocution due to the transmission of high voltage power.

After the rectification of the power from $A C$ to $D C$ in the piezoelectric transducer stage, the power flows into the DC boost converter stage where the voltage is amplified as observed from Figure 3. Similar to the rectifier circuit analogy, the DC booster also experiences some power loss due to the components used to constitute the circuit design. These losses are listed in Table 6 and were considered before designing the Simulink model observed from Figure 3.

From Table 6 , it can be evidently noticed that the power losses experienced from the DC boost block are mainly due to 
TABLE 7: Overall power generation from inverter stage.

\begin{tabular}{lc}
\hline Parameter & Value \\
\hline Voltage (V) & 188 \\
Current $(\mathrm{mA})$ & 0.99 \\
Power $(\mathrm{W})$ & 0.186 \\
\hline
\end{tabular}

TABLE 8: Power losses in the inverter.

\begin{tabular}{lc}
\hline & Inverter losses \\
\hline Snubber resistance & 5000 \\
Snubber capacitance & Inf \\
IGBT switching losses & 1.18 \\
IGBT forward drop & 0 \\
IGBT resistance & 0.001 \\
Number of IGBTs & 6 \\
Total IGBT losses & 1.18 \\
Total inverter loss (W) & 1.185 \\
\hline
\end{tabular}

the switching losses caused from the control of the MOSFET triggered using the pulse width modulation block and various other power losses due to the internal resistance of various components involved in the circuitry of the design block. Moreover, the losses of this block also include a snubber circuit similar to that of the circuit observed in the rectifier block. After the DC boosting stage the DC output was converted into AC input as per the simulation model shown in Figure 3 and it had a voltage value of $188 \mathrm{~V}$ of $V_{\text {ac/phase }}$. Then the overall power generation estimation added up to a value given in Table 7.

However, this stage of power generation also experienced power losses due to the diodes and its switching of frequency to a level which was considered in the Simulink model. It is noteworthy to note that inverter circuitry was not only used to convert DC into AC but also to step it up to a frequency that is feasible and standardized to the grid frequency range for further transmission. Moreover, the losses that were considered in the process of designing the inverter circuit analogy is listed and evaluated in Table 8 .

From Table 8 , it is notably evident that the power loss from this inverter circuit analogy is mainly due to the IGBT's switching and power loss caused due to them. In addition to the IGBTs, the power losses experienced in the inverter block are also due to the snubber circuitry that is present to absorb any shock within the system in case of a circuit failure.

Furthermore, the overall power loss of the proposed system also constitutes minute level of noises caused due to the transmission of power over various components and LC filter was used. Therefore, these types of noises also constitute certain amount of losses that define the signal-tonoise ratio and determine the power quality of the overall power generation. In addition to the filtering effect, the proposed system also minimizes the loss in power quality and reduces white filter noise.

4.1. Total Power Generation Summary. Table 9 perceives the required information that estimates the total power generated
TABLE 9: Total power generation summary.

\begin{tabular}{|c|c|c|c|}
\hline Duration & Traffic rate/hr & $\begin{array}{c}\text { Speed of } \\
\text { travel (kmph) }\end{array}$ & $\begin{array}{c}\text { Energy generated } \\
(\mathrm{kWhr})\end{array}$ \\
\hline \multirow{8}{*}{ Peak time } & \multirow{4}{*}{500} & 60 & 73.55 \\
\hline & & 80 & 136.8 \\
\hline & & 100 & 254.2 \\
\hline & & 120 & 469.04 \\
\hline & \multirow{4}{*}{300} & 60 & 60.81 \\
\hline & & 80 & 105.78 \\
\hline & & 100 & 183.024 \\
\hline & & 120 & 281.424 \\
\hline \multirow{8}{*}{ Off-peak time } & \multirow{4}{*}{100} & 60 & 20.81 \\
\hline & & 80 & 35.26 \\
\hline & & 100 & 61.01 \\
\hline & & 120 & 93.81 \\
\hline & \multirow{4}{*}{50} & 60 & 10.4 \\
\hline & & 80 & 17.63 \\
\hline & & 100 & 30.51 \\
\hline & & 120 & 46.91 \\
\hline \multirow{8}{*}{ Peak time } & \multirow{4}{*}{400} & 60 & 76.782 \\
\hline & & 80 & 136.83 \\
\hline & & 100 & 244.03 \\
\hline & & 120 & 375.23 \\
\hline & \multirow{4}{*}{200} & 60 & 40.76 \\
\hline & & 80 & 70.52 \\
\hline & & 100 & 122.02 \\
\hline & & 120 & 187.62 \\
\hline \multirow{7}{*}{ Off-peak time } & \multirow{4}{*}{25} & 100 & 15.252 \\
\hline & & 80 & 8.825 \\
\hline & & 120 & 23.452 \\
\hline & & 60 & 20.81 \\
\hline & \multirow{3}{*}{100} & 80 & 35.26 \\
\hline & & 100 & 61.01 \\
\hline & & 120 & 93.81 \\
\hline
\end{tabular}

for various traffic rates traveling at speed of $60,80,100$, and $120 \mathrm{kmph}$ (average speed limits of Dubai with heavy traffic).

It is noteworthy to note that the overall power generation results obtained are for a single lane road and the minimum speed limit is $60 \mathrm{kmph}$. Also, Dubai was considered as an example for power generation estimation and these parameters are liable to change with the change of vehicle mass, speed, and temperature, that is, set with respect to the MATLAB script.

4.2. Estimation of Greenhouse Gas Emission. Carbon emission is keen factor that causes global warming. This factor was considered in producing green energy as the actual system may not emit any but the vehicle source does. However, this source is mainly constrained to vehicles powered on diesel, petrol, or any source of fuel; and in near future due to advancement in the field of smart technology and 
TABLE 10: Overall carbon emission per annum.

\begin{tabular}{|c|c|c|c|c|c|c|c|c|c|c|c|c|}
\hline Month & 1 & 2 & 3 & 4 & 5 & 6 & 7 & 8 & 9 & 10 & 11 & 12 \\
\hline Peak traffic rate & 500 & 300 & 400 & 300 & 300 & 200 & 200 & 200 & 300 & 500 & 500 & 500 \\
\hline Off-peak traffic rate & 100 & 100 & 100 & 50 & 50 & 50 & 25 & 50 & 50 & 100 & 200 & 200 \\
\hline Number of days & 31 & 28 & 31 & 30 & 31 & 30 & 31 & 31 & 30 & 31 & 30 & 31 \\
\hline Carbon emission/day & 1214.4 & 910.8 & 683.1 & 683.1 & 683.1 & 531.3 & 923.45 & 531.3 & 683.1 & 1214.4 & 1669.8 & 1669.8 \\
\hline Carbon emission/month & 37646.4 & 25502.4 & 21176.1 & 20493 & 21176.1 & 15939 & 28626.95 & 16470.3 & 20493 & 37646.4 & 50094 & 51763.8 \\
\hline Annual carbon emission & \multicolumn{12}{|c|}{347.03} \\
\hline
\end{tabular}

TABLE 11: Overall carbon emission.

\begin{tabular}{|c|c|c|c|c|c|c|c|c|}
\hline Duration & traffic rate/hour & Hours & $\begin{array}{c}\text { Occurrence rate } \\
\text { per year }\end{array}$ & Type of vehicle & Count & $\begin{array}{l}\mathrm{CO}_{2} \text { emission } \\
\text { rate }(\mathrm{g} / \mathrm{km})\end{array}$ & $\begin{array}{c}\mathrm{CO}_{2} \\
\text { emission } \\
\text { (kg/hour) }\end{array}$ & $\begin{array}{c}\mathrm{CO}_{2} \\
\text { emission } \\
\text { (kg/day) }\end{array}$ \\
\hline \multirow[t]{2}{*}{ Peak time } & \multirow[t]{2}{*}{500} & \multirow{2}{*}{6} & \multirow{4}{*}{2} & BMW & \multirow{2}{*}{250} & 292 & \multirow{2}{*}{126.5} & \multirow{4}{*}{1214.4} \\
\hline & & & & Land Cruiser & & 214 & & \\
\hline \multirow{2}{*}{ Off-peak time } & \multirow{2}{*}{100} & \multirow{2}{*}{18} & & BMW & \multirow{2}{*}{50} & 292 & \multirow{2}{*}{25.3} & \\
\hline & & & & Land Cruiser & & 214 & & \\
\hline \multirow{2}{*}{ Peak time } & \multirow{2}{*}{500} & \multirow[t]{2}{*}{6} & & BMW & \multirow{2}{*}{250} & 292 & \multirow{2}{*}{126.5} & \\
\hline & & & 2 & Land Cruiser & & 214 & & 1669.8 \\
\hline \multirow{2}{*}{ Off-peak time } & \multirow{2}{*}{200} & \multirow{2}{*}{18} & & BMW & \multirow{2}{*}{100} & 292 & \multirow{2}{*}{50.6} & \\
\hline & & & & Land Cruiser & & 214 & & \\
\hline \multirow{2}{*}{ Peak time } & \multirow{2}{*}{200} & \multirow{2}{*}{16} & & BMW & \multirow{2}{*}{100} & 292 & \multirow{2}{*}{50.6} & \\
\hline & & & 2 & Land Cruiser & & 214 & & 923.45 \\
\hline \multirow{2}{*}{ Off-peak time } & \multirow{2}{*}{25} & \multirow{2}{*}{18} & & BMW & 12.5 & 292 & 6.325 & \\
\hline & & & & Land Cruiser & & 214 & & \\
\hline Peak time & 300 & 6 & & BMW & 60 & 292 & 30.36 & \\
\hline & & & 5 & Land Cruiser & & 214 & & 273.24 \\
\hline Off-peak time & 50 & 18 & & BMW & 10 & 292 & 5.06 & \\
\hline & & & & Land Cruiser & & 214 & & \\
\hline Peak time & 200 & 6 & & BMW & 200 & 292 & 101.2 & \\
\hline & & & 1 & Land Cruiser & 200 & 214 & 101.2 & 1062.6 \\
\hline Off-peak time & 50 & 18 & & BMW & 50 & 292 & 25.3 & \\
\hline & & & & Land Cruiser & & 214 & & \\
\hline Peak time & 400 & 6 & & BMW & 400 & 292 & 202.4 & \\
\hline & & 0 & 1 & Land Cruiser & 700 & 214 & 202.4 & 2125.2 \\
\hline Off-peak time & 100 & 18 & & BMW & 100 & 292 & 50.6 & \\
\hline & & & & Land Cruiser & & 214 & & \\
\hline Peak time & 300 & 6 & & BMW & 300 & 292 & 151.8 & \\
\hline & & & 1 & Land Cruiser & & 214 & & 1821.6 \\
\hline Off-peak time & 100 & 18 & & BMW & 100 & 292 & 50.6 & \\
\hline Oil-pean tinte & 100 & 10 & & Land Cruiser & & 214 & & \\
\hline
\end{tabular}

smart vehicles, carbon emission from this proposed system will be nullified as smart vehicles use electricity to travel. Table 8 estimates amount of carbon emission for the proposed systems with the following assumptions:

(i) Traffic rate ranges from 25 to 500 vehicles per hour.

(ii) Vehicles present are only BMWs and Land Cruisers (these are the two main vehicles that contribute most of the $\mathrm{CO}_{2}$ emission in UAE).
Table 11 (provided in Appendix) was estimated to determine the $\mathrm{CO}_{2}$ emission and the carbon emission from a road having speed bumps emanating $0.1 \mathrm{~kg} / \mathrm{km}$ more than the specified carbon dioxide emission rate. Using the information from Table 11, the overall carbon emission per year from this type of the proposed system is evaluated in Table 10.

The estimation of annual carbon emission for the proposed system was found to be 353 tonnes. 


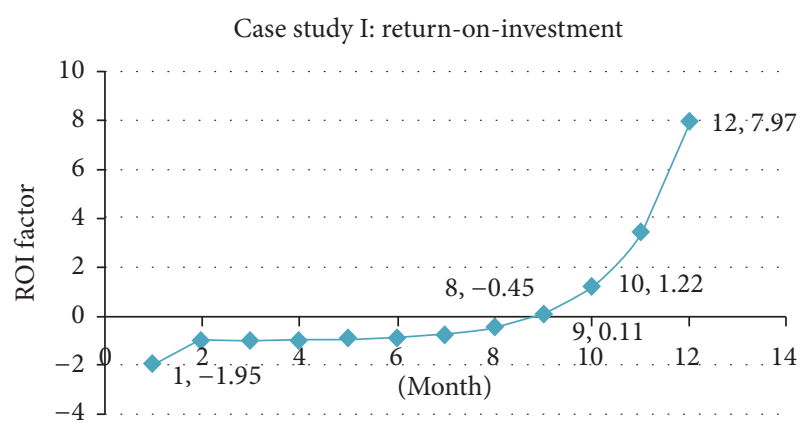

FIgURE 4: Graphical representation of ROI for Table 13.

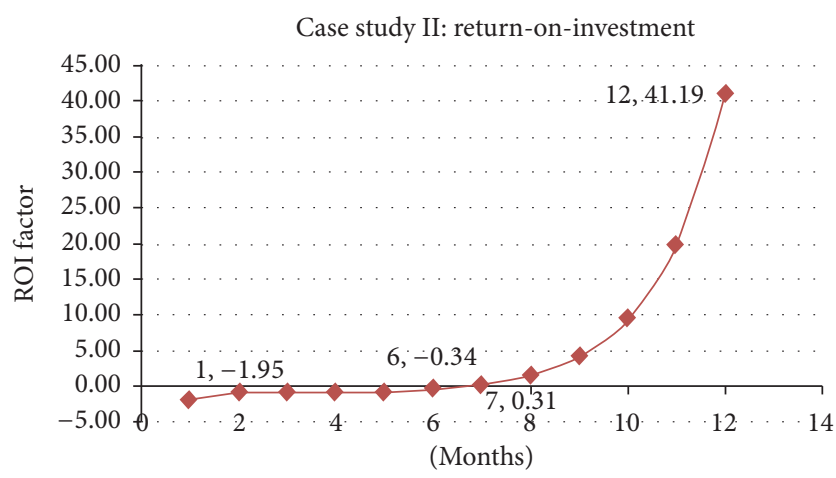

FIgURE 5: Graphical representation of ROI for Table 14.

\section{Economic Analysis}

Using data obtained from Table 9, annual power generation was estimated along with implementation expenditures to formulate a cash flow represented in Table 13 (Appendix) when speed of travel is $100 \mathrm{kmph}$. Using the data Figure 4 represents the return-on-investment.

From Table 13, it is evident that the entire proposed system has an internal-rate-of-return of $96 \%$ with a returnon-investment by the end of July as indicated in Figure 4 for a loan of AED 550,000 taken at an interest rate of $7 \%$. The high rate of internal-rate-of-return is due to the elongated loan payback period of three years. This estimation is purely based on profit from energy production rated at $0.23 \mathrm{AED} / \mathrm{kW} / \mathrm{hr}$ of energy production. Similarly, business analysis was carried out for vehicles traveling at $60 \mathrm{kmph}$, $80 \mathrm{kmph}$, and $120 \mathrm{kmph}$ that produced an internal-rate-ofreturn of $81 \%, 90 \%$, and $100 \%$ with a return-on-investment by end of November, August, and June, respectively, for the same load and interest rate, and the cash flow was formulated and represented in Tables 12, 14, and 15 (Appendix).

Similarly, from Table 14 , it is evident that the entire proposed system has an internal-rate-of-return of $90 \%$ with a return-on-investment at the end of August as indicated in Figure 5 for a loan of AED 550,000 taken at an interest rate of $7 \%$ when the speed of travel was $80 \mathrm{kmph}$. Following a similar estimation as observed in Table 15 when speed of travel is $120 \mathrm{kmph}$, it is evident that the entire proposed system has an internal-rate-of-return of $100 \%$ with a return-on-investment

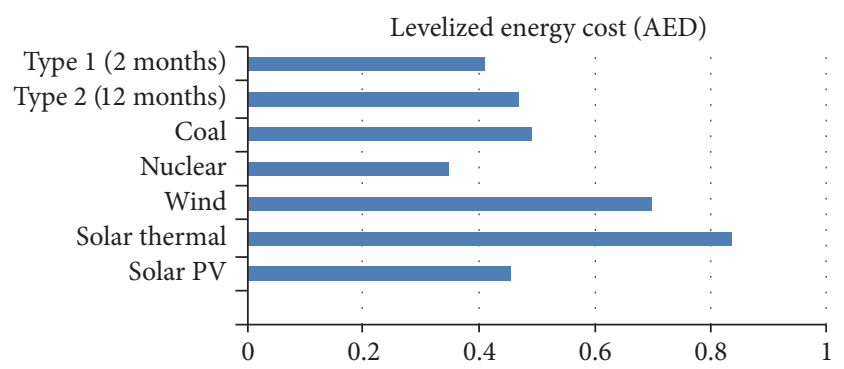

Figure 6: Levelized Energy Cost Graph.

at the end of June for a loan of AED 550,000 taken at an interest rate of $7 \%$.

In addition to the cash flow estimation, the power generation estimation of available renewable energy sources and its cost of implementation are normalized using levelized energy cost system. The cost system was estimated for the country United Arab Emirates. This was done to develop a bar graph to compare cost and power generation to the proposed system models in this research project.

The levelized costs observed from Figure 6 were obtained from NREL Energy Analysis softaware. It is evident that the LEC of nuclear energy is the least, but it produces hazardous side effects and requires proper disposal system. Next, the LEC of the proposed system is the least with two months of maintenance investment which is the most economical with no side effects. However, power generation from the proposed system has minimal LEC in comparison to solar one which is the main source of renewable energy ( $0.455 \mathrm{AED} / \mathrm{kW} / \mathrm{hr})$. Hence it can be concluded that the proposed system designs are cost effective and efficient in comparison to other sources of renewable energy applicable to UAE as traffic is abundantly available. It must be also noted that traffic rate was limited to just one system. This refers to a single lane system. Thus, restricting the annual traffic rate to that particular lane which affects the overal LEC.

\section{Conclusion}

This paper emphasized generating green and sustainable energy and this was implicated on generation of green energy from speed humps by integrating the concept of compressed air. First, traffic rate was 500 vehicles per hour with vehicle traveling at a speed of 100,80 , and $120 \mathrm{kmph}$ yielding about 255,137 , and $469 \mathrm{kWh}$, respectively. Then it was found that entire system can be implemented using a year loan of AED 550,000 at an interest rate of $7 \%$. The returnon-investment factor was at end of July, August, and June with $96 \%$, 90\%, and 100\% internal-rate-of-return factor for one system, respectively. After that, it was found that system yields about 347 tonnes of carbon which is purely due to petrol and diesel vehicles and this value may significantly be nullified once all means of transport are smart vehicles. Finally, all renewable energy sources were compared with proposed system methodology and it was concluded that the proposed system has better LEC in comparison to other renewable energies present in United Arab Emirates. 


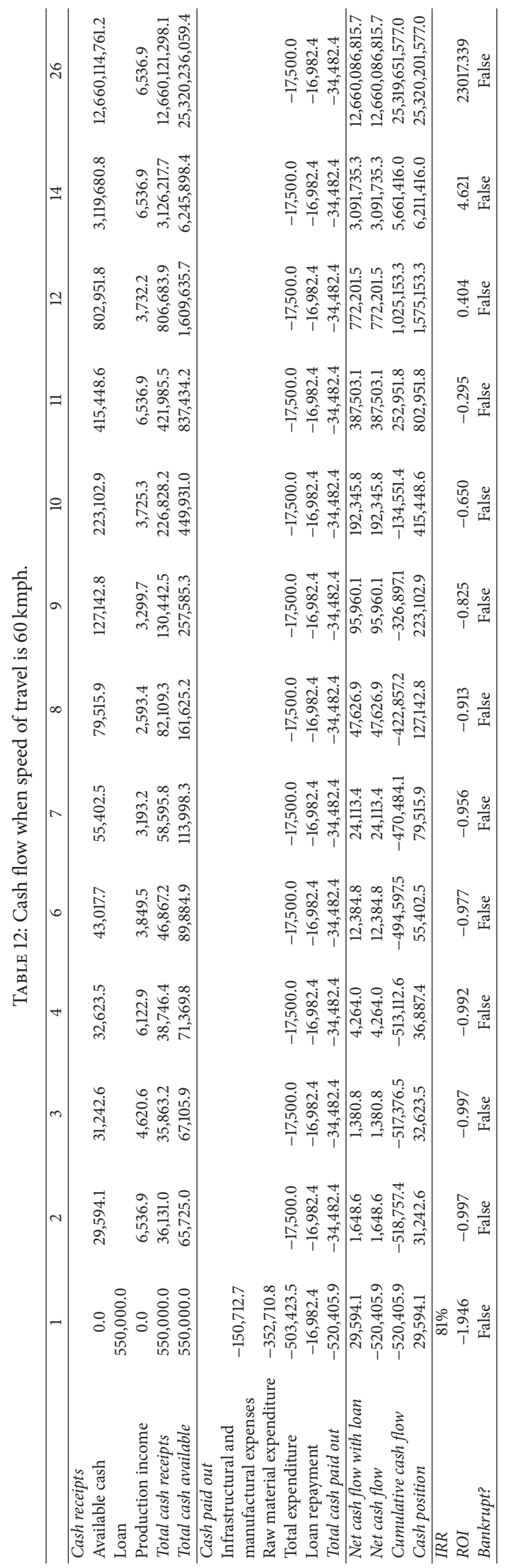




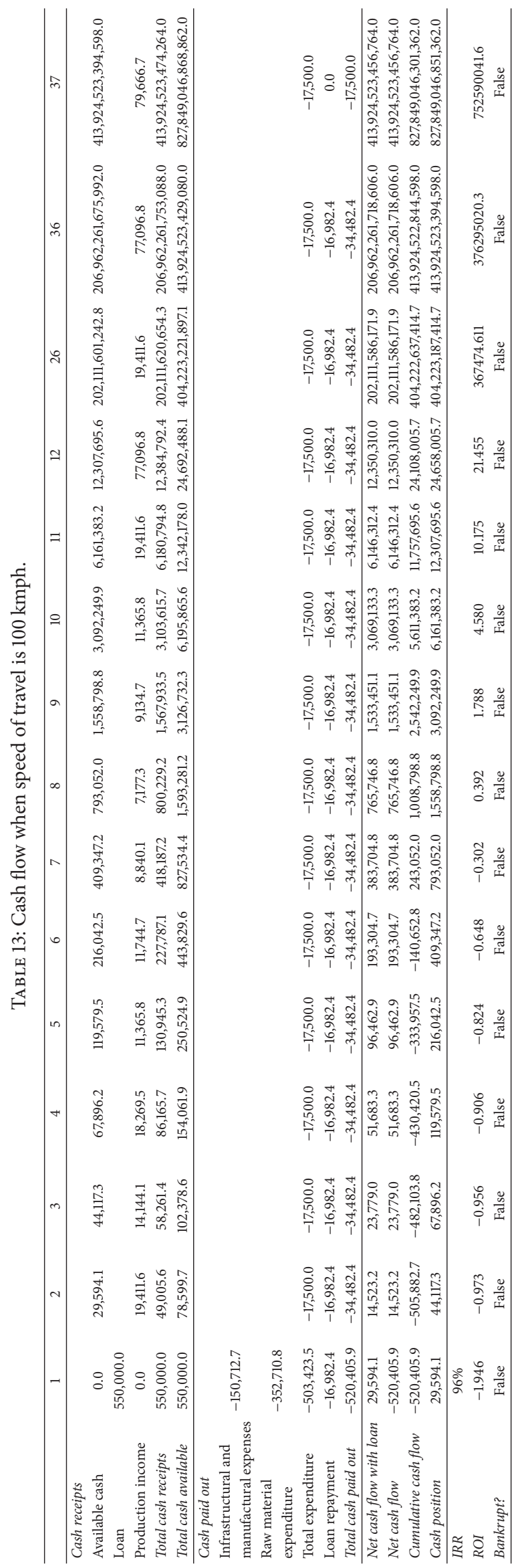




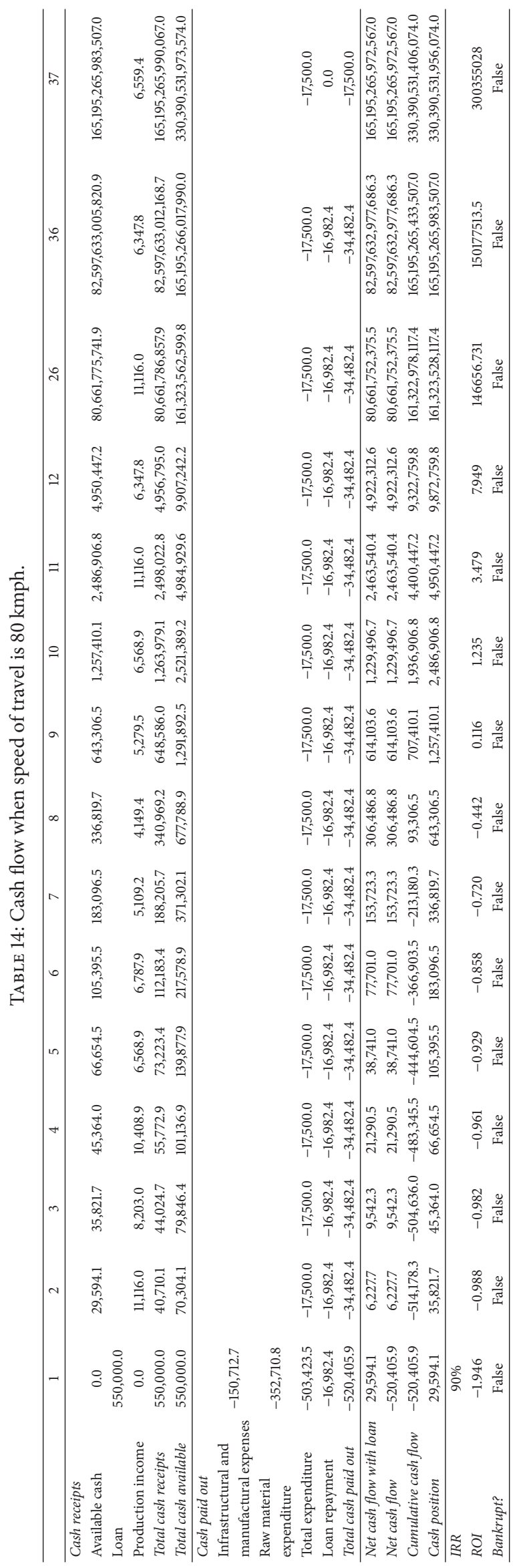




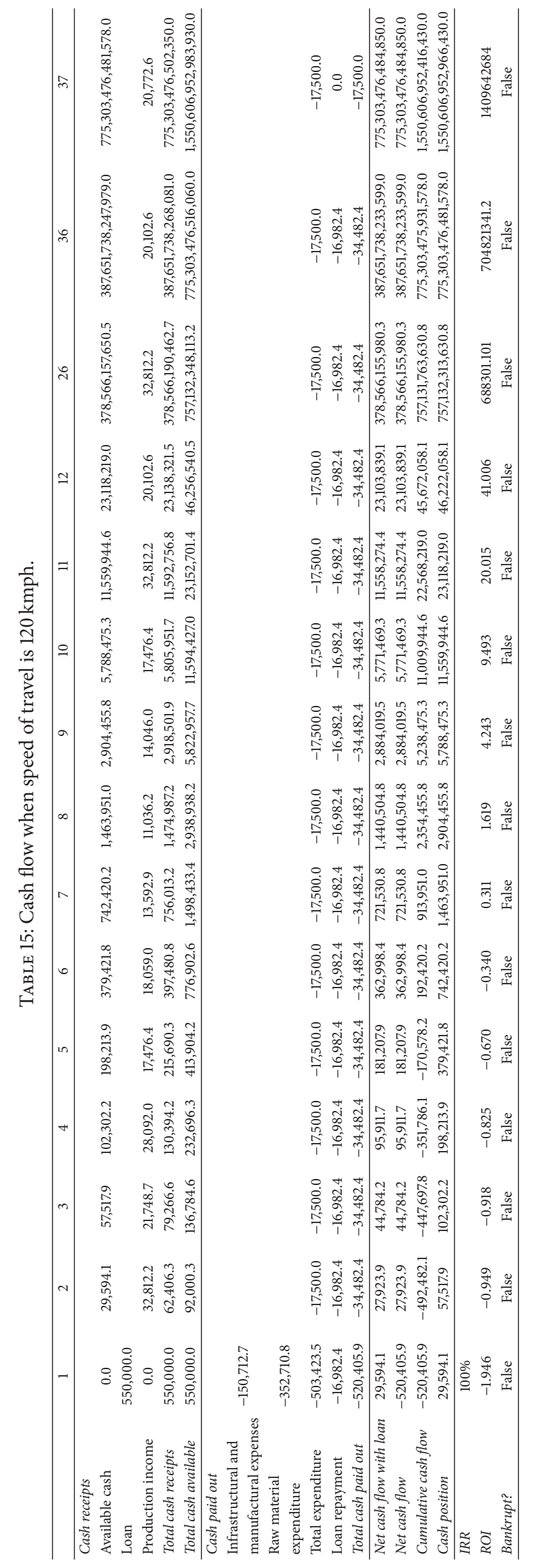




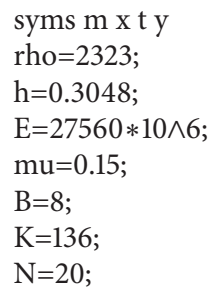

Algorithm 1: Continued. 


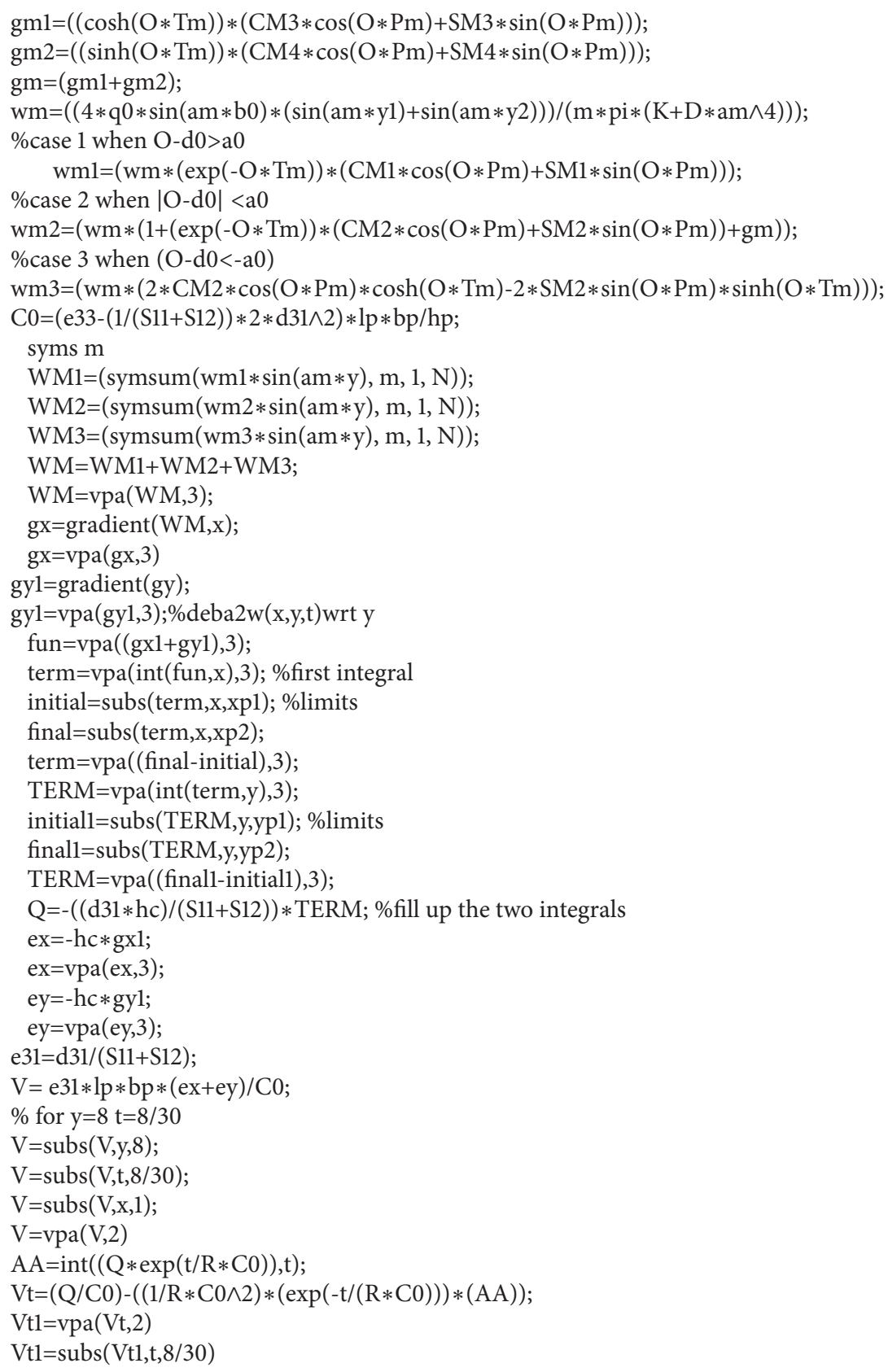

Algorithm 1: MATLAB script.

\section{Appendix}

\section{Piezoelectric Output Equations}

Kirchhoff-Love plate theory is

$$
\text { Bending Rigidity }(D)=\frac{E h^{3}}{12\left(1-\mu^{2}\right)} \text {. }
$$

Fourier series is

$$
\begin{aligned}
\omega(x, y, t) & =\sum_{m=1}^{\infty} \omega_{m}(x, t) \sin \left(\frac{m \pi}{b} y\right) \\
& =\sum_{n=1}^{N} \omega_{n}(x, t) \sin \left(\frac{m \pi}{b} y\right), \\
f_{m}(x, t) & =\frac{2}{b} \int_{0}^{b} F(x, y, t) \sin \left(\frac{m \pi}{b} y\right) d y .
\end{aligned}
$$


Piezoelectric equations are

$$
C_{0}=\left[\epsilon_{33}-\left(s_{11}+s_{12}\right)^{-1} 2 d_{31}^{2}\right] \frac{l_{p} b_{p}}{h_{p}} .
$$

MATLAB Script. See Algorithm 1.

Estimation of Carbon Emission. See Tables 11-15.

\section{Nomenclature}

\author{
$D: \quad$ Bending rigidity $\left(\mathrm{Nm}^{2}\right)$ \\ E: $\operatorname{Energy}(\mathrm{J})$ \\ $h$ : Plank's constant \\ $\mu$ : Poisson ratio \\ $F: \quad \operatorname{Load}(\mathrm{N})$ \\ $\omega:$ Displacement in 3D $(\mathrm{m})$ \\ $\omega_{m}$ : Displacement for " $m$ " terms $(\mathrm{m})$ \\ $f_{m}$ : Load for " $m$ " terms $(\mathrm{N})$ \\ $\epsilon_{33}$ : Permittivity \\ $s_{11}$ : Elastic compliance constant \\ $s_{12}$ : Elastic compliance constant \\ $d_{31}$ : Piezoelectric constant \\ $l_{p}$ : Length of piezoelectric transducer $(\mathrm{m})$ \\ $b_{p}$ : Width of piezoelectric transducer $(\mathrm{m})$ \\ $h_{p}$ : Height of piezoelectric transducer $(\mathrm{m})$ \\ $C_{0}$ : Output capacitance $(\mathrm{F})$.
}

\section{Competing Interests}

The authors declare that there is no conflict of interests regarding the publication of this paper.

\section{Acknowledgments}

Heriot-Watt University has provided the entire essential support academically and software requirements.

\section{References}

[1] C. Maxwell, "Law of conservation of energy," http://www.britannica.com/science/conservation-of-energy.

[2] H. Najini and S. A. Muthukumaraswamy, "Investigation on the selection of piezoelectric materials for the design of an energy harvester system to generate energy from traffic," International Journal of Engineering and Applied Science, vol. 3, no. 2, pp. 4349, 2016.

[3] Z. Zhang, H. Xiang, and Z. Shi, "Modeling on piezoelectric energy harvesting from pavements under traffic loads," Journal of Intelligent Material Systems and Structures, vol. 27, no. 4, pp. 567-578, 2016.

[4] J. N. Reddy, Theory and Analysis of Elastic Plates and Shells, CRC Press, New York, NY, USA, 2006.

[5] C.-N. Xu, M. Akiyama, K. Nonaka, K. Shobu, and T. Watanabe, "Electrical output performance of pzt-based piezoelectric ceramics," in Proceedings of the Tenth IEEE International Symposium on Applications of Ferroelectrics (ISAF '96), vol. 2, pp. 967-970, IEEE, East Brunswick, NJ, USA, 1996.
[6] H. Zhao, Y. Tao, Y. Niu, and J. Ling, "Harvesting energy from asphalt pavement by piezoelectric generator," Journal Wuhan University of Technology, Materials Science Edition, vol. 29, no. 5, pp. 933-937, 2014.

[7] M. Goldfarb and L. D. Jones, "On the efficiency of electric power generation with piezoelectric ceramic," Journal of Dynamic Systems, Measurement and Control, Transactions of the ASME, vol. 121, no. 3, pp. 566-571, 1999.

[8] Q. Ibrahim, "Design, implementation and optimisation of an energy harvesting system for vehicular ad hoc networks' road side units," IET Intelligent Transport Systems, vol. 8, no. 3, pp. 298-307, 2014.

[9] J. Wang, Z. Shi, H. Xiang, and G. Song, "Modeling on energy harvesting from a railway system using piezoelectric transducers," Smart Materials and Structures, vol. 24, no. 10, Article ID 105017, 2015.

[10] N. Mohan, T. M. Undeland, and W. P. Robbins, Power Electronics: Converters, Applications, and Design, John Wiley \& Sons, New York, NY, USA, 3rd edition, 2003. 

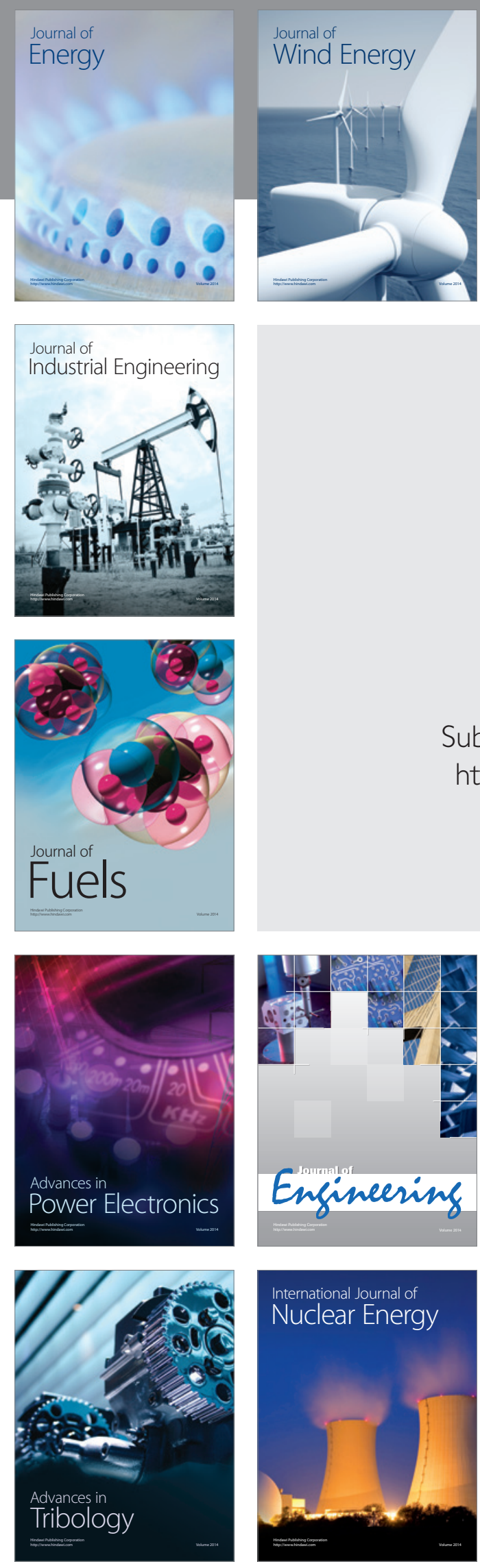

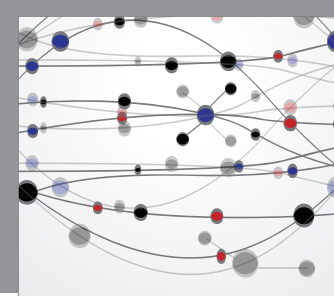

The Scientific World Journal
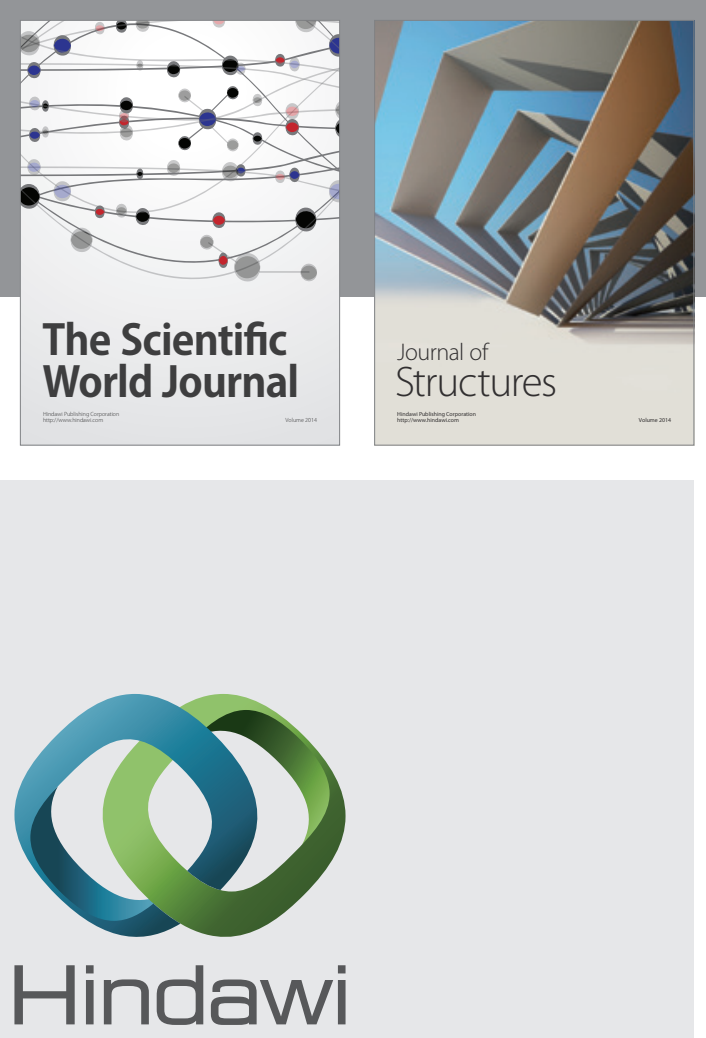

Submit your manuscripts at

https://www.hindawi.com
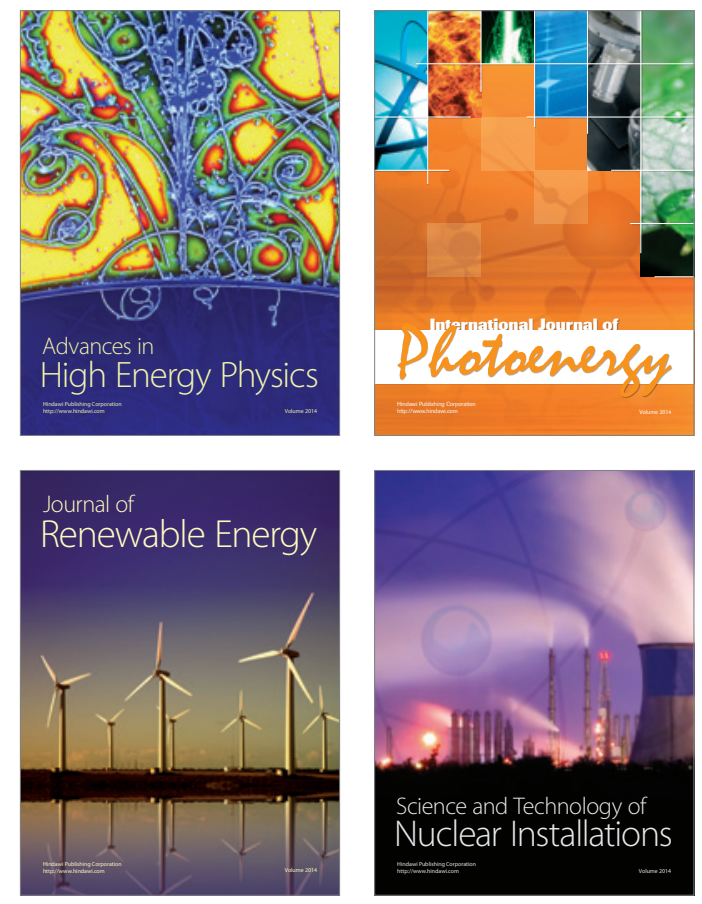
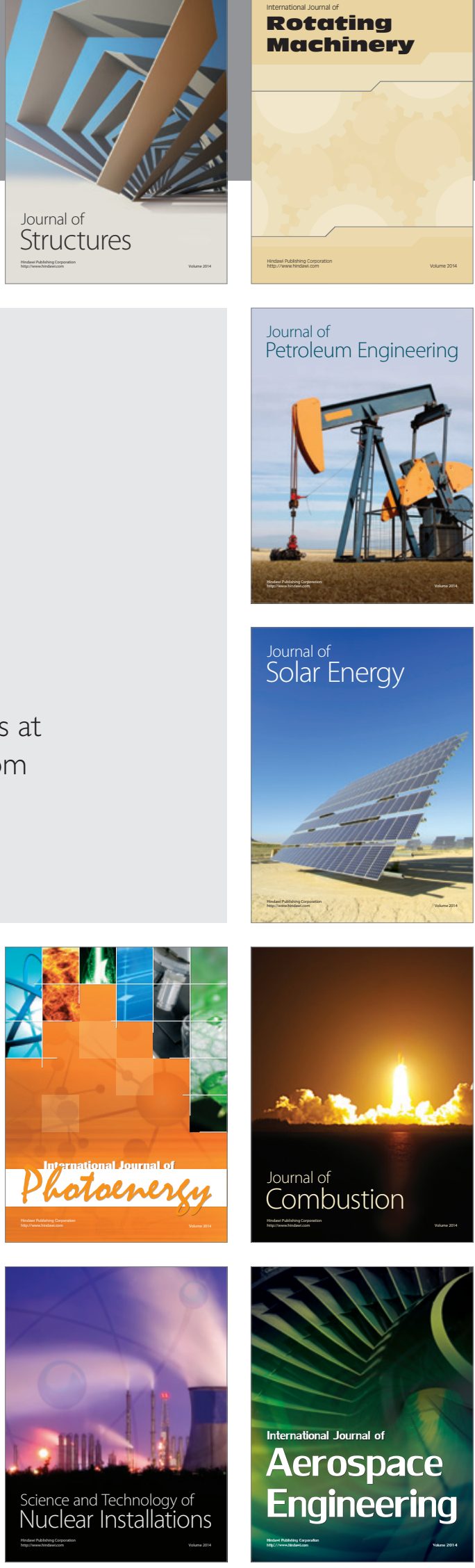